\title{
IMPLEMENTASI DENSITY-BASED CLUSTERING PADA SEGMENTASI CITRA Betta Fish
}

\author{
Yunda Heningtyas ${ }^{1)}$, Fathur Rahmi' ${ }^{2}$, Kurnia Muludi ${ }^{3)}$ \\ 1,2,3 Jurusan Ilmu Komputer Fakultas MIPA, Universitas Lampung \\ 1,2,3 Jl Soemantri Brojonegoro No. 1 Gedong Meneng Bandar Lampung \\ Email: '1yunda.heningtyas@fmipa.unila.ac.id,_fathurrahmi15@gmail.com
}

\begin{abstract}
During the COVID-19 pandemic, the number of ornamental fish enthusiasts has increased, especially those of the Betta Fish species. Betta Fish is a type of ornamental Fish with various species with beautiful colors and morphology, especially the shape of the tail. The more diverse the color patterns of the Fish and the unique shape, the more expensive the selling price of this type of ornamental Fish. The market demand for Betta Fish is getting higher, causing the selling price of Betta Fish also to increase. However, not all ornamental fish lovers recognize the species name of the Betta Fish. For this reason, a pattern recognition-based system is needed that can recognize Betta Fish species. Pattern recognition has several stages, namely segmentation, extraction, and classification. This study aims to separate the object from the background on a digital image. The dataset used is 160 images consisting of 40 images of each species, namely Halfmoon, Double Tail, Serit, and Plakat. The first step is to convert the image into a saturation and intensity color model. The method used in the segmentation process is Density-Based Clustering. Density-Based Clustering is a segmentation method by forming clusters based on the density level of the object area. The segmentation process using the DensityBased Clustering method achieves an accuracy rate of $92.82 \%$.
\end{abstract}

Keyword: Betta Fish, Density-Based Clustering, HSI, Image Recognition, Image Segmentation

\begin{abstract}
Abstrak
Pada masa pandemi COVID-19, peminat ikan hias semakin meningkat jumlahnya, terutama peminat ikan hias spesies Betta Fish. Betta Fish merupakan jenis ikan hias dengan spesies yang beragam dengan keindahan warna dan morfologi tubuh, terutama bentuk ekornya. Semakin beragam corak warna ikan dan bentuk ekor yang unik, semakin mahal harga jual dari ikan hias jenis ini. Permintaan pasar terhadap ikan Betta Fish semakin tinggi sehingga menyebabkan harga jual Betta Fish juga meningkat. Namun, tidak semua pecinta ikan hias mengenali nama spesies dari ikan Betta Fish. Untuk itu, diperlukan sebuah sistem berbasis pattern recognition yang dapat mengenali spesies Betta Fish. pattern recognition memiliki beberapa tahapan, yaitu segmentasi, ekstraksi, dan klasifikasi. Penelitian ini bertujuan untuk memisahkan (segmentasi) objek dengan background pada citra digital. Dataset yang digunakan berjumlah 160 citra dengan jumlah citra untuk setiap spesies adalah 40 citra. Spesies Betta Fish yang digunakan adalah Halfmoon, Double Tail, Serit dan Plakat. Tahapan pertama dengan mengonversi citra menjadi model warna saturation dan intensity. Proses segmentasi pada penelitian ini menggunakan metode Density-Based Clustering. Density-Based Clustering merupakan salah satu metode segmentasi yang mengelompokkan citra menjadi beberapa cluster berdasarkan tingkat density dari masing-masing region atau objek. Hasil segmentasi metode Density-Based Clustering pada citra Betta Fish mencapai tingkat akurasi sebesar $92,82 \%$.
\end{abstract}

Kata Kunci: Betta Fish, density based clustering, HSI, image recognition, segmentasi citra

\section{Pendahuluan}

Indonesia memiliki keanekaragaman hayati terdiri dari beragam jenis flora dan fauna yang tumbuh dan berkembang dengan baik, termasuk ikan hias. Ikan hias di Indonesia dibagi berdasarkan lingkungan hidupnya yaitu ikan hias air tawar dan ikan hias air laut. Dalam kondisi pandemi COVID-19, ikan hias air tawar menjadi salah satu peliharaan yang banyak diminati oleh masyarakat
Indonesia. Selain bentuk dan warna tubuh yang unik dan indah, pemeliharaan ikan hias air tawar cukup murah dan tidak menggunakan banyak usaha. Ikan cupang yang memiliki nama lain Betta Fish merupakan salah satu ikan yang banyak diminati. Keunikan Betta Fish tidak hanya pada corak dan warnanya, Betta Fish memiliki bentuk ekor yang unik dan berbeda antar spesies [1]. Inilah yang menjadi daya tarik utama dari Betta Fish. Bentuk ekor Betta Fish sangat beragam, tergantung padda spesiesnya. 
Beberapa spesies yang banyak diminati memiliki bentuk ekor menyerupai mahkota (crown tail), setengah bulan sabit (Halfmoon), slayer, dan bulat (rounded tail). Indonesia memiliki 48 spesies Betta Fish [2]. Jumlah variasi spesies Betta Fish yang beragam memiliki nilai jual yang juga beragam. Beberapa spesies ikan Betta Fish memiliki range harga jual yang jauh berbeda sehingga kesalahan dalam pemilihan spesies ataupun pembelian ikan ini menyebabkan kerugian yang cukup banyak. Selain itu, tidak semua pecinta ikan hias memahami setiap spesies Betta Fish.

Solusi yang ditawarkan untuk menyelesaikan permasalahan di atas adalah membuat sebuah sistem yang dapat mengenali berbagai spesies Betta Fish. Sistem ini menerapkan teknologi pattern recognition dengan beberapa tahapan yaitu preprocessing, segmentasi, ekstraksi fitur, dan klasifikasi. Pattern recognition dapat diartikan sebagai proses mengidentifikasi suatu objek menjadi kelas atau kategori tertentu. Tahap preprocessing merupakan tahap awal sebelum melakukan segmentasi. Tahap ini bertujuan untuk mengolah citra supaya citra tersebut dapat digunakan sebagai input pada proses segmentasi. Segmentasi merupakan tahap pemisahan citra menjadi 2 bagian atau lebih yang memiliki informasi penting. Prosedur pemisahan atau pembagian citra menjadi beberapa segmen, region atau objek dapat berdasarkan kesamaan warna, tekstur, maupun kecerahan dari region pada citra itu sendiri [3]. Pembagian citra berdasarka region bertujuan untuk memisahkan foreground (objek) dan background (region selain objek). Hasil segmentasi citra harus mencapai nilai dengan tingkat akurasi yang tinggi sehingga sistem akan mendapatkan hasil ekstraksi fitur yang maksimal. Hasil ektraksi fitur yang baik akan menyebabkan nilai klasifikasi yang optimal [4].

Wang [5] melakukan percobaan untuk mensegmentasi citra 2 Dimensi menggunakan model hidden Markov random field (HMRF) dan algoritma expectation-maximization (EM). Wang menggunakan perbandingan segmentasi K-Means dengan HMRF-EM. Penerapan metode K-Means tidak dapat menghilangkan noise pada citra namun menghasilkan tingkat akurasi yang cukup baik. Penerapan HMRF-EM berhasil meningkatkan akurasi hasil segmentasi menjadi $81,17 \%$. Salah satu penerapan metode HMRF-EM pada segmentasi citra ikan Tuna dilakukan oleh Azhar dkk. Namun, perbedaan intensitas piksel pada citra ikan Tuna tidak dapat diatasi menggunakan metode segmentasi HMRF-EM saja. Azhar dkk [6] mengkombinasikan beberapa metode selama proses segmentasi ikan tuna. Metode Density-Based Clustering digunakan pada tahap segmentasi, Hidden Markov Random Field dan algoritma expectationmaximization digunakan untuk memperbaiki tepi objek pada hasil segmentasi. Kombinasi tiga metode tersebut memberikan tingkat akurasi sebesar 96.69\%.

Penelitian yang dilakukan oleh Putra [7] menggunakan metode Density-Based Clustering untuk proses segmentasi citra remote sensing laut yang digunakan untuk mengidentifikasi zona kedalaman laut dari penginderaan jarak jauh. Metode DBSCAN diberikan proses pra pengolahan citra baik itu penyesuaian ukuran citra dan kuantisasi warna citra sebelum dilakukan proses DBSCAN agar proses metode DBSCAN bisa bekerja lebih efisien. Metode Density-Based Clustering ini menghasilkan zona kedalaman laut yang ada pada citra yang diujikan. Uji coba hasil segmentasi menggunakan Density-Based Clustering dengan proses pengolahan citra berupa kuantisasi warna dengan presentase keberhasilan sebesar $96,3 \%$.

Penelitian ini menggunakan metode Density-Based Clustering untuk proses segmentasi ikan Beta Fish. Letak perbedaan dalam penelitian ini dengan penelitian sebelumnya adalah penerapan metode Density-Based Clustering dengan objek pengamatan yaitu ikan hias spesies Betta Fish. Citra Betta Fish yang diambil secara langsung pada akuarium dan tidak memerlukan proses perubahan background. Sistem ini dapat membantu sistem identifikasi ikan hias Betta Fish menjadi lebih baik dengan meningkatkan akurasi sistem.

\section{Metode}

Tahapan penelitian yang dilakukan dengan menggunakan metode Density-Based Clustering terdiri dari beberapa tahapan, yaitu preprocessing, segmentasi, serta hasil dan evaluasi. Tahapan penelitian dapat dilihat pada Gambar 1.

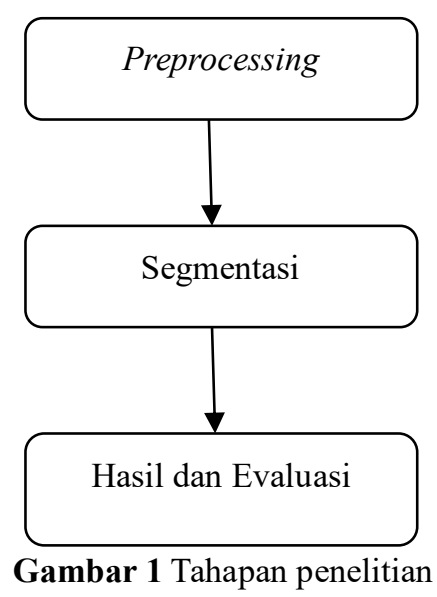

\subsection{Preprocessing}

Citra RGB hasil akuisisi dikonversi menjadi model warna HSI (Hue, Saturation dan Intensity). Hue mengandung warna-warna asli (kuning, violet, dan merah). Penggunaan warna Hue sering digunakan untuk membedakan cahaya, redness, dengan greenness. Saturation mengindikasikan banyaknya warna putih yang terkandung pada sebuah warna [8]. Misalkan warna merah merupakan warna jenuh sedangkan warna pink merupakan warna merah yang telah bercampur dengan warna putih dengan komposisi tertentu (tingkat kejenuhan warna rendah) [8]. Intensity merupakan atribut yang menyatakan jumlah cahaya yang berhasil ditangkap retina mata. Intensity tidak mempedulikan komposisi warna [8]. Komponen warna HSI dapat dilihat pada Gambar 2. 


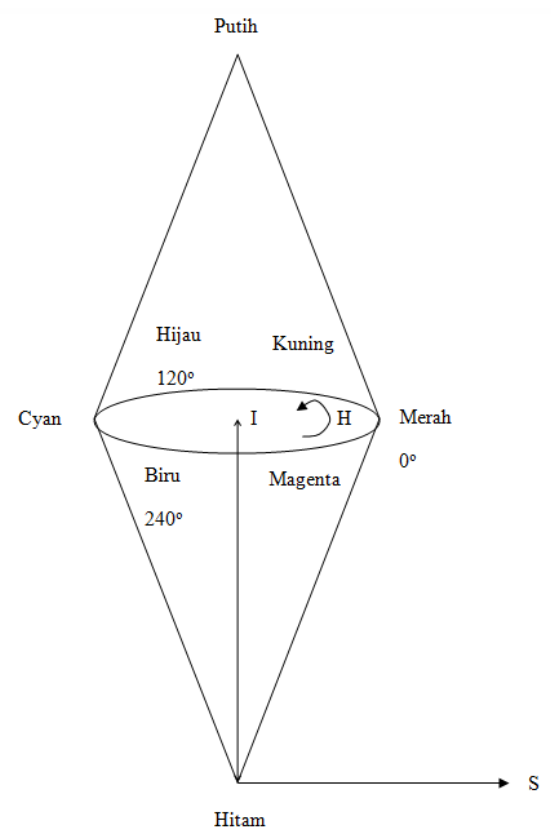

Gambar 2 Warna HIS [8]

Nilai RGB dinormalisasikan menjadi range $[0,1]$. Intensity (I) didefinisikan menggunakan rumus 1 [9].

$$
I=\frac{1}{3}(R+B+G)
$$

Nilai intensity berada pada range [0,1]. Komponen nilai Hue didefinisikan dalam rumus 2 [9].

$$
H=\left\{\begin{array}{cc}
\theta & \text { if } B \leq G \\
360-\theta & \text { if } B>G
\end{array}\right.
$$

where

$$
\theta=\cos ^{-1}\left[\frac{\{(R-G)+(R-B)\} / 2}{\sqrt{(R-G)^{2}+(R-B)(G-B)}}\right]
$$

Komponen Saturation diperoleh dari rumus 4 [9].

$$
S=1-\frac{3}{(R+G+B)}\{\min (R, G, B)\}
$$

Adapun nilai Saturation berada diantara 0 sampai 1 [9]. Adapun warna yang digunakan dalam proses segementasi adalah Saturation dan Intensity. Tabel 1 merupakan contoh hasil preprocessing Betta Fish.

Tabel 1. Preprocessing Result

\begin{tabular}{ccc}
\hline $\begin{array}{c}\text { Spesies } \\
\text { Betta Fish }\end{array}$ & Citra Asli & $\begin{array}{c}\text { Hasil } \\
\text { preprocessing }\end{array}$ \\
\hline Double Tail & & \\
\hline
\end{tabular}

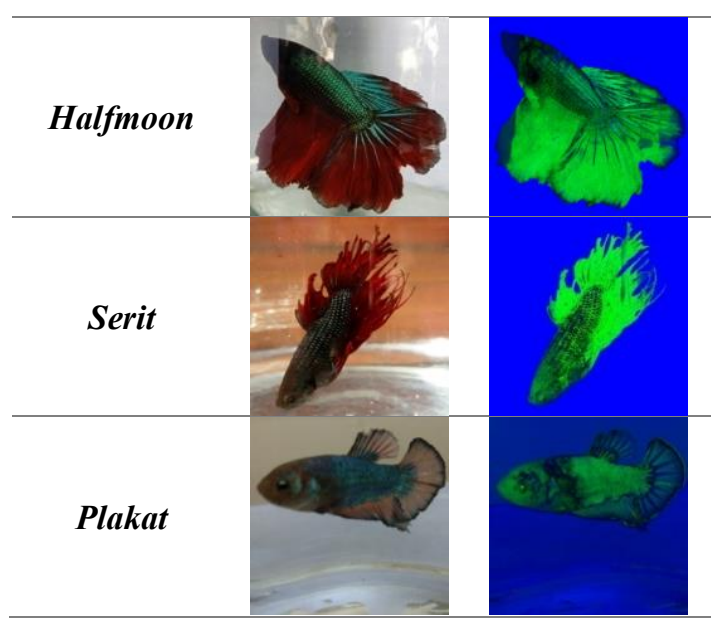

\subsection{Segmentasi}

Segmentasi pada citra dilakukan untuk memisahkan beberapa objek sehingga objek tersebut dapat digunakan pada proses selanjutnya. Objek yang akan disegmentasi pada citra Betta Fish terdiri dari 2 yaitu objek ikan dan background. Density-Based Clustering merupakan algoritma yang membagi area berdasarkan kepadatan data menjadi cluster. Maing-masing cluster tersebut memiliki bentuk acak dalam database spatial [10]. Algoritma Density-Based Clustering menegaskan bahwa sebuah cluster memiliki banyak titik. Neighborhood dari radius yang diberikan dari setiap titik minimal harus memiliki jumlah minimum poin. Jumlah minimum poin yang dimaksud adalah density dari neighborhood harus lebih dari beberapa threshold tertentu. [10]

Adapun tahapan segmentasi citra Density-Based Clustering [11] sebagai berikut:

a. Penentuan Parameter Input

Metode Density-Based Clustering memerlukan dua parameter input. Input dalam penelitian ini terdiri dari dua parameter cluster. Cluster yang pertama mengelompokkan objek yang terdeteksi sebagai ikan. Cluster kedua mengelompokkan objek selain ikan yang selanjutnya disebut background.

b. Penempatan data ke dalam cluster

Density-Based Clustering mencari wilayah pada citra berwarna yang dapat disegmentasi menggunakan perhitungan jangkauan spasial (SpatialEps) dan jangkauan warna (ColorEps). Perhitungan tersebut dilakukan pada semua pixel citra yang akan disegmentasi [10]. Data yang ditempatkan dalam cluster secara acak terlebih dahulu dengan memberikan label pada setiap titik.

c. Menghitung titik pusat cluster

Minimum point (MinPts) yang berhasil dicapai dalam jangkauan point tersebut dapat secara spasial maupun warna. Point tersebut membentuk cluster baru dengan intinya (core point) masing-masing [10]. Titik pusat diperoleh dengan mencari titik yang berada pada nilai batas berdasarkan banyaknya data.

d. Pengelompokkan data pada titik pusat

Density-Based Clustering mengumpulkan point yang saling terkoneksi secara spasial serta core point yang 
memiliki kesamaan warna secara iteratif. Proses berhenti ketika tidak ada lagi point yang dapat ditambahkan ke dalam cluster [10]. Setiap data yang memiliki jarak terdekat berdasarkan tingkat kemiripan dari titik pusat akan membentuk sebuah cluster yang diperoleh dengan menggunakan euclidean distance.

e. Penyelesaian proses segmentasi citra

Setelah semua data telah terproses maka akan menghasilkan suatu citra hasil pemisahan antara objek dan background.

\subsection{Hasil Segmentasi dan Evaluasi}

Hasil segmentasi Density-Based Clustering berupa citra ikan dengan 2 objek yang dapat dipisahkan. Objek tersebut adalah citra ikan Betta Fish dengan background. Tahap evaluasi dilakukan dengan membandingkan seluruh citra hasil segmentasi metode Density-Based Clustering dengan citra hasil segmentasi manual. Segmentasi manual diperoleh dari pengeditan menggunakan Adobe Photoshop. Perbandingan dilakukan pada jumlah nilai piksel antara citra Betta Fish yang tersegmentasi menggunakan Density-Based Clustering dengan tersegmentasi manual. Hasil perbandingan digunakan sebagai tingkat akurasi dari penerapan metode DensityBased Clustering pada citra Betta Fish. Evaluasi dihitung menggunakan rumus 5 .

Evaluasi $=\frac{\sum \text { nilai pixel citra hasil segmentasi }}{\sum n \text { ilai pixel citra hasil segmentasi manual }} 100 \%$

\section{Hasil dan Analisis}

Hasil akhir dari proses segmentasi pada penelitian ini adalah objek Betta Fish dengan background berwarna hitam. Tabel 2 merupakan hasil proses segmentasi Betta Fish.

Tabel 2. Hasil Segmentasi Density-Based Clustering

\begin{tabular}{ccc}
$\begin{array}{c}\text { Spesies } \\
\text { Betta Fish }\end{array}$ & $\begin{array}{c}\text { Citra } \\
\text { Akuisisi }\end{array}$ & $\begin{array}{c}\text { Hasil } \\
\text { Segmentasi }\end{array}$ \\
\hline Double Tail & & \\
Halfmoon & \\
\hline
\end{tabular}

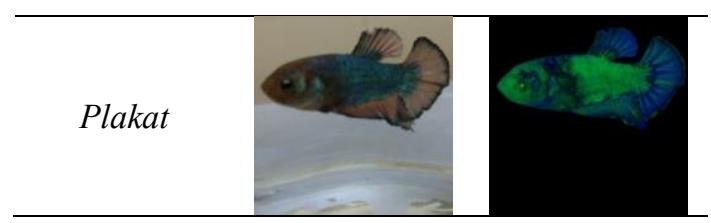

Tahap selanjutnya adalah Evaluasi. Evaluasi digunakan untuk mendapatkan nilai akurasi dari hasil segmentasi. Evaluasi dihitung dengan membandingkan masing-masing jumlah nilai pixel citra hasil segmentasi menggunakan metode Density-Based Clustering dan jumlah nilai pixel citra hasil segmentasi secara manual. Contoh hasil segmentasi metode Density-Based Clustering dan nilai akurasinya dapat dilihat pada Tabel 3.

Tabel 3. Hasil Segementasi dan Akurasi Density Based Clustering

\begin{tabular}{|c|c|c|c|}
\hline $\begin{array}{l}\text { Spesies } \\
\text { Betta Fish }\end{array}$ & $\begin{array}{c}\text { Segmentasi } \\
\text { Density-Based } \\
\text { Clustering }\end{array}$ & $\begin{array}{c}\text { Segmentasi } \\
\text { Manual }\end{array}$ & $\begin{array}{c}\text { Akurasi } \\
\text { (\%) }\end{array}$ \\
\hline $\begin{array}{c}\text { Double } \\
\text { Tail }\end{array}$ & & & 99.0657 \\
\hline Halfmoon & & & 96.2808 \\
\hline Serit & & & 97.4787 \\
\hline Plakat & & & 99.5581 \\
\hline
\end{tabular}

Grafik perbandingan hasil akurasi dari segmentasi citra Betta Fish dalam penelitian ini dapat dilihat pada Gambar 2. 


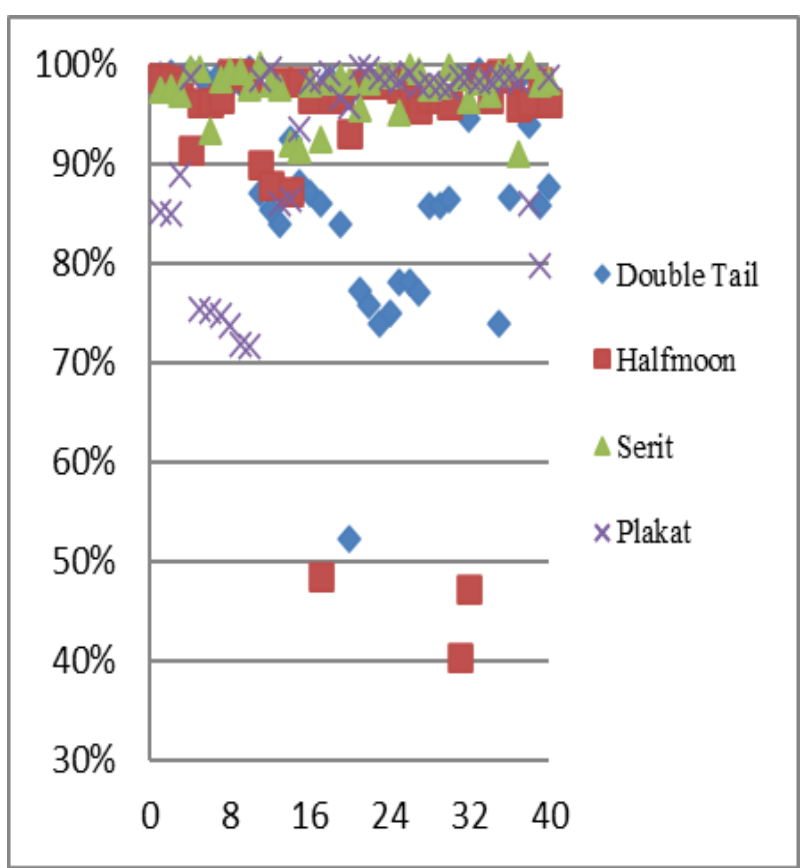

Gambar 2. Perbandingan Hasil Akurasi Citra Betta Fish

Dari perbandingan hasil akurasi segmentasi citra Betta Fish dapat dilihat bahwa citra Betta Fish memiliki tingkat akurasi yang cenderung sama pada setiap jenisnya yang memiliki akurasi lebih dari 70\%. Berdasarkan Gambar 2, empat citra memiliki akurasi kurang dari 70\% yaitu tiga citra Betta Fish Halfmoon dan satu citra Betta Fish Double Tail.

Rata-rata hasil akurasi segmentasi citra Betta Fish spesies Double Tail sebesar 88,61\% Betta Fish spesies Halfmoon sebesar 92,68\%, Betta Fish spesies Serit sebesar 97,62\%, dan Betta Fish spesies Plakat sebesar 92,36\%. Rata-rata akurasi hasil segmentasi secara keseluruhan mencapai 92,82\%.

Citra input dapat mempengaruhi seluruh hasil segmentasi. Kualitas citra input yang baik akan meningkatkan hasil segmentasi objek Betta Fish. Analisis kesalahan hasil segmentasi dapat dilihat pada Tabel 2.

Tabel 2. Analisis Kesalahan Hasil Segmentasi

\begin{tabular}{cccc}
\hline $\begin{array}{c}\text { Spesies } \\
\text { Betta } \\
\text { Fish }\end{array}$ & $\begin{array}{c}\text { Hasil } \\
\text { Segmentasi }\end{array}$ & $\begin{array}{c}\text { Akuras } \\
\text { i }\end{array}$ & $\begin{array}{l}\text { Analisis } \\
\text { Kesalahan }\end{array}$ \\
\hline $\begin{array}{c}\text { Double } \\
\text { Tail }\end{array}$ & & $52 \%$ & $\begin{array}{l}\text { Tingkat } \\
\text { saturation dan } \\
\text { intensity pada } \\
\text { preprocessing } \\
\text { tidak jauh beda } \\
\text { antara objek } \\
\text { dengan } \\
\text { background } \\
\text { sehingga }\end{array}$ \\
\hline$n$ & & $49 \%$ & \\
\end{tabular}

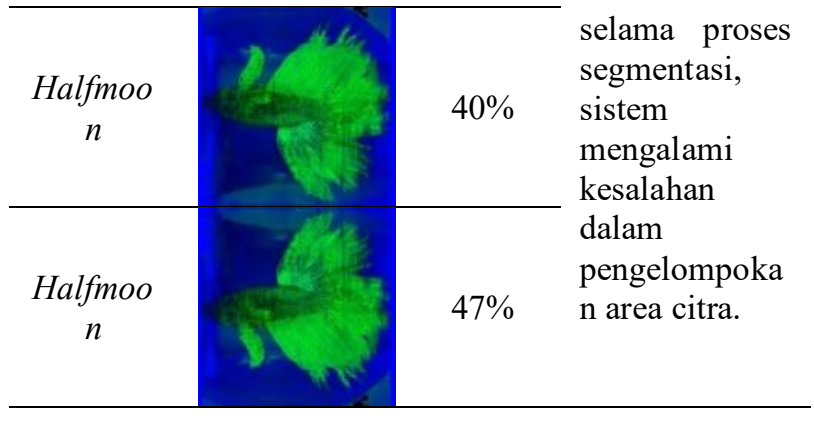

\section{Kesimpulan}

Metode segmentasi Density Based Clustering mampu membedakan objek pada citra Double Tail, Halfmoon, Plakat, dan Serit dengan objek background. Tingkat akurasi penerapan metode ini pada citra Betta Fish sebesar $92,82 \%$.

\section{Daftar Pustaka}

[1] Gumilang, B. Inggayuing, I. K. Artawan, and N. L. P. M. Widiyanti, "Variasi Intensitas Cahaya Mengakibatkan Perbedaan Kecepatan Regenerasi Sirip Kaudal Ikan Cupang (Betta splendens) Dipelihara Di Rumah Kos.," J. Pendidik. Biol., vol. 3, no. 2, 2016.

[2] Z. Bintang, Panduan Praktis Budidaya dan Pemeliharaan Cupang. Jakarta: Penebar Swadaya, 2017.

[3] A. Jati, G. Singh, S. Koley, A. Konar, R. Ajoy, and C. Chakraborty, "A novel segmentation approach for noisy medical images using Intuitionistic fuzzy divergence with neighbourhood-based membership function," J. Microsc., 2014, doi: 10.1111/jmi.12200.

[4] T. Sutoyo, E. Mulyanto, V. Suhartono, O. D. Nurhayati, and Wijanarto, TEORI PENGOLAHAN CITRA DIGITAL. Yogyakarta: Andi Offset, 2009.

[5] Q. Wang, "HMRF-EM-image: Implementation of the Hidden Markov Random Field Model and its Expectation-Maximization Algorithm," no. July 2012, 2012.

[6] R. Azhar, A. Z. Arifin, and W. N. Khotimah, "Integrasi Density-Based Clustering dan HMRFEM Pada Ruang Warna HSI untuk Segmentasi Citra IkanTuna," Inspir. J. Teknol. Inf. dan Komun., vol. 6, no. 1, pp. 28-37, 2016.

[7] I. M. S. Putra, "Segmentasi Citra Remote Sensing Laut Dengan Metode Clustering Dbscan," Maj. Ilm. Teknol. Elektro, vol. 12, no. 2, 2013.

[8] R. C. Gonzalez and R. E. Woods, "Digital Image Processing Third Edition Pearson," 2008.

[9] A. Taguchi, "Color Systems and Color Image Enhancement Methods," ECTI Trans. Comput. Inf. Technol., vol. 10, no. 2, pp. 97-110, 20161.

[10] A. Moreira and M. Santos, "1 Density-based 
clustering algorithms _ DBSCAN and SNN," 2005.

[11] A. S. Devi, I. K. G. D. Putra, and I. M. Sukarsa, "Implementasi Metode Clustering DBSCAN pada
Proses Pengambilan Keputusan," Lontar Komput. J. Ilm. Teknol. Inf., vol. 6, no. 3, p. 185, 2015, doi: 10.24843/1kjiti.2015.v06.i03.p05. 